\title{
Surgical treatment for basilar invagination with irreducible atlantoaxial dislocation: transoral atlantoaxial reduction plate fixation vs occipitocervical fixation
}

Xiaobao Zou ${ }^{1,2+}$, Bieping Ouyang ${ }^{1,2+}$, Haozhi Yang ${ }^{2 \dagger}$, Binbin Wang ${ }^{2}, \mathrm{Su} \mathrm{Ge}^{2}$, Yuyue Chen ${ }^{2}$, Ling $\mathrm{Ni}^{2}$, Shuang Zhang ${ }^{2}$, Hong Xia ${ }^{2}$, Jingcheng Yang ${ }^{3^{*}}$ and Xiangyang $\mathrm{Ma}^{1,2^{*}}$

\begin{abstract} between the TARP and OF groups postoperatively. reduction plate, Occipitocervical fusion, Internal fixation

\footnotetext{
*Correspondence: yangjcnyjz@126.com; maxy1001@126.com

${ }^{+}$Xiaobao Zou, Beiping Ouyang and Haozhi Yang contributed equally and

should be regarded as co-first authors.

${ }^{3}$ Department of Spinal Surgery, Nanfang Hospital, Southern Medical

University, No.1838 North of Guangzhou Road, Guangzhou 510515, People's

Republic of China

${ }^{1}$ The First School of Clinical Medicine, Southern Medical University, No.1838 North of Guangzhou Road, Guangzhou 510515, People's Republic of China

Full list of author information is available at the end of the article
}

Background: Transoral atlantoaxial reduction plate (TARP) fixation or occipitocervical fixation (OF) is an effective treatment for basilar invagination (BI) with irreducible atlantoaxial dislocation (IAAD). But, all current clinical studies involved a single surgical procedure. The clinical effects of TARP and OF operation for BI with IAAD have yet to be compared. We therefore present this report to compare the treatment of TARP and OF procedure for BI with IAAD

Methods: Fifty-six patients with BI with IAAD who underwent TARP or OF operation from June 2011 to June 2017 were retrospectively analyzed. Among these, 35 patients underwent TARP operation (TARP group), and 21 patients underwent OF operation (OF group). We compared the difference of clinical, radiological, and surgical outcomes

Results: Compared with OF group, the operative time and blood loss in TARP group were lower. There was no statistical difference in the atlantodental interval (ADI), clivus canal angle (CCA), cervicomedullary angle (CMA), distance between the top of the odontoid process and the Chamberlain line (CL) and Japanese Orthopaedic Association (JOA) score between the TARP and OF groups preoperatively, but the improvements of these parameters in the TARP group were superior to those in the OF group postoperatively. The fusion rates were higher in the TARP group than those in the OF group at the early stage postoperatively.

Conclusions: TARP and OF operations are effective surgical treatment for BI with IAAD, but the performance of reduction and decompression and earlier bone fusion rates of TARP procedure are superior to those of OF.

Keywords: Basilar invagination, Irreducible atlantoaxial dislocation, Transoral approach, Transoral atlantoaxial

C The Author(s). 2020 Open Access This article is licensed under a Creative Commons Attribution 4.0 International License, which permits use, sharing, adaptation, distribution and reproduction in any medium or format, as long as you give appropriate credit to the original author(s) and the source, provide a link to the Creative Commons licence, and indicate if changes were made. The images or other third party material in this article are included in the article's Creative Commons licence, unless indicated otherwise in a credit line to the material. If material is not included in the article's Creative Commons licence and your intended use is not permitted by statutory regulation or exceeds the permitted use, you will need to obtain permission directly from the copyright holder. To view a copy of this licence, visit http://creativecommons.org/licenses/by/4.0/. The Creative Commons Public Domain Dedication waiver (http://creativecommons.org/publicdomain/zero/1.0/) applies to the data made available in this article, unless otherwise stated in a credit line to the data. 


\section{Background}

Basilar invagination (BI) is a relatively common congenital or developmental anomaly of the craniocervical junction characterised by prolapse of the odontoid process into the foramen magnum, generally accompanied by irreducible atlantoaxial dislocation (IAAD). The condition may result in spinal cord and brainstem (medullary) compression, thus leading to severe neurological injury. Persistent serious compression can cause respiratory disturbance, with high mortality rates $[1,2]$. As a result of abnormal structure, complicated anatomy, deep position, and proximity to the vertebral artery and medulla, surgical treatment of BI with IAAD is difficult and poses a high risk $[3,4]$. Transoral atlantoaxial reduction plate (TARP) fixation [5-8] and occipitocervical fixation (OF) [9-13] are two frequently-used surgical approaches for treating BI with IAAD. Several current clinical studies [5-13] have confirmed the effectiveness of TARP and OF operations, but all involved a single surgical procedure. Therefore, we conducted a study to compare the treatment of two surgical procedures for BI with IAAD.

\section{Methods}

\section{Patients and data collection}

In this retrospective study, we enrolled patients diagnosed with BI with IAAD undergoing a TARP or OF operation between June 2011 and June 2017. Skull traction was performed in all patients for 1 week preoperatively, and no sings of reduction was found in all cases. All patients underwent transoral anterior release before TARP or OF procedure. Then, patients who had oropharyngeal diseases or small oral space underwent OF procedure, otherwise, both TARP and OF procedures could be used. Exclusion criteria were (1) previous surgery such as posterior decompression of the foramen magnum or decompression of the anterior arch of $\mathrm{C} 1$; (2) a cervical intraspinal or osseous tumour; (3) severe osseous anomalies of the craniovertebral junction, hindering measurement; and (4) less than 12 months of follow-up.

According to our criteria, a total of 56 patients were included in the study. Thirty-five patients underwent TARP surgery (TARP group), and 21 cases were treated with OF surgery (OF group). Each patient's clinical data were reviewed carefully. Data collection included demographics, clinical manifestations, radiological parameters, surgical details such as internal fixation technique, intraoperative blood loss, operative time, and complications.

\section{Surgical procedures}

Preoperative preparation: All patients were required to gargle 3-6 times per day with vinegar chlorhexidine $0.02 \%$ for 3 days before surgery. A preoperative professional dental cleaning was performed. All patients received intravenous broad-spectrum antibiotics $30 \mathrm{~min}$ before operation.

\section{TARP}

This surgical technique has been previously described by Yin et al. [5, 6]. The main points of the technique were introduced below.

Under general anaesthesia with transnasopharyngeal intubation, the patient was positioned supine with skull traction of 4-12 kg. After conventional oral cleaning, the face and oropharyngeal cavities were disinfected repeatedly with an iodophor, normal saline, hydrogen peroxide, and chlorhexidine before placement of the surgical drapes. Posterior pharyngeal wall was incised lengthwise by $3-4 \mathrm{~cm}$ to expose the anterior structure of the $\mathrm{C} 1-\mathrm{C} 2$ after subperiosteal exfoliation of the mucosa and muscle. The anterior hyperplastic scar tissue, articular capsule and intraarticular cartilage were then thoroughly resected to loosen atlantoaxial joint. If the release was unsatisfactory, the extent of the release was expanded, even if it was necessary to cut the odontoid process and alar ligaments. Then, the articular surface of the bilateral mass joints was ground off with a high-speed bur in preparation for bone grafting. According to the measurement of the distance between the entry points of the bilateral $\mathrm{C} 1$ lateral mass screws, an appropriate size TARP was selected. Then, two screws were used to fix the TARP to the anterior surface of the atlas. After a temporary reduction screw was implanted into the $\mathrm{C} 2$ vertebral body through the open slip section in the central part of the TARP, the upper arm of a reduction forceps was installed to hold the crossbar of the TARP and the inferior arm hold the temporary reduction screw. Then, the forceps handles were closed to distract the C1-C2 joint for lengthways reduction, and the nut on the upper arm was then turned to push $\mathrm{C} 1$ back towards the odontoid process for horizontal reduction. After the reduction was confirmed to be satisfactory on intraoperative radiographs, retropedicle screws or vertebral screws were implanted in $\mathrm{C} 2$ to solidly fix the TARP, and the temporary reduction screw was then removed. An intraoperative radiograph further confirmed the location of the screws and the reduction of the $\mathrm{C} 1-\mathrm{C} 2$ joint. After the autogenous iliac bone was grafted into the bilateral lateral mass joints space, the muscular and mucosal layers of the wound were closed.

OF

Under general anaesthesia with transnasopharyngeal intubation, the patient was positioned supine first with skull traction of 4-12 kg. Transoral anterior release procedure, as described in TARP operation, was performed primarily. Subsequently, the patient was changed to prone position with the same weight skull traction. The 
skin was incised longitudinally for about $8 \mathrm{~cm}$ along the posterior midline of the neck from the occipital to the C2 spinous process. The occipital bone, the posterior arch of $\mathrm{C} 1$, and the lateral mass of $\mathrm{C} 2$ were exposed by subperiosteal dissection in both directions, and the attachment of the $\mathrm{C} 2$ spinous process was retained. The C2 bilateral pedicle screw paths were prepared, and then screws were placed after tapping. If the pedicle screws were unsuitable for $\mathrm{C} 2$ fixation due to anatomical variations, the translaminar screws or pars screws were used instead for $\mathrm{C} 2$ fixation. Then an occipital plate was placed. The rods were then contoured and loaded onto the $\mathrm{C} 2$ screw heads and occipital plate on both sides and locked. The C1 posterior arch, the C2 lamina, and the lower part of the occipital plate were ground off with a high-speed bur to prepare the bone-graft bed. The autogenous iliac cancellous bone was grafted. After a negative pressure drainage tube was placed, the incision was sutured layer by layer.

\section{Postoperative management}

The nasal trachea cannula was removed $24-48 \mathrm{~h}$ after operation, and the nasogastric feeding tube was removed in 7-10 days after the wound healing was confirmed by an electronic laryngoscope. Ultrasonic nebulisation and $0.02 \%$ chlorhexidine gargling were performed 3-6 times per day for 1 week. All patients received intravenous broad-spectrum antibiotics for 3 days postoperatively.

\section{Radiological and neurological evaluation}

The cervical X-ray radiographs, computed tomography (CT) scans and magnetic resonance imaging (MRI) were obtained before surgery, at discharge and then at each follow-up. Patients were followed up at 3, 6 and 12 months and then once per year or whenever needed. Postoperative surgery-related or nonsurgical-related complications were recorded. Bone fusion was determined by bone bridge formation showed on CT scan. Patients' neurologic status was assessed using the Japanese Orthopaedic Association (JOA) score before surgery, at discharge and then at each follow-up.

The atlantodental interval (ADI), the clivus canal angle (CCA) and the distance between the top of the odontoid process and the Chamberlain line $(C L)$ were measured on the preoperative, discharge and 3-month follow-up $\mathrm{CT}$ images to evaluate the reduction of $\mathrm{C} 1-\mathrm{C} 2$. The ventral compression of the spinal cord and medulla was assessed by the cervicomedullary angle (CMA) measured on the sagittal MRI scans.

\section{Statistical analysis}

Statistical analysis was performed using the SPSS 19.0 software (IBM, Armonk, NY, USA). The comparison between the two groups were performed using the independent-samples $t$ test for quantitative data, and the Pearson's chi-squared test for categorical data. The pairedsamples $t$ test was used to analyze any statistical difference between the pre- and postoperative measurements in each group. The level of significance was set at $p<.05$.

\section{Results}

\section{Clinical and surgical characteristics}

The clinical and surgical information are summarized in Table 1. No significant statistical differences were found both in gender ratio and age between the TARP and OF groups. The most frequent clinical symptom was extremities weakness, followed by numbness, occiput and neck pain, dystaxia, dyspnea and the others in both groups. There was no significant difference in the frequencies of symptoms and symptom treatment interval between groups. The rates of concomitant malformation were not different between the two groups.

All 56 patients underwent successful surgeries (Figs. 1 and 2). No major neurovascular injury occurred during the surgical procedure. A significant statistical difference was found between the TARP $(227.6 \pm 61.5 \mathrm{~min})$ and OF $(325.2 \pm 123.4 \mathrm{~min})$ groups for the mean operative time $(p<.01)$. The blood loss was significantly lower in the TARP group (123.1 \pm $54.9 \mathrm{~mL})$ than that in the OF group $(271.4 \pm 142.8$ $\mathrm{mL})(p<.01)$. After surgery, nonsurgical-related complications occurred in three patients $(8.5 \%)$ in the TARP group and one patient $(4.7 \%)$ in the OF group $(p=.59)$. The average follow-up time of the TARP group was $36.6 \pm 16.0$ months (range $12-72$ months), which had no statistical difference compared with that in the OF group $(41.6 \pm 18.1$ months, range $12-84$ months; $p=.29$ ).

\section{Radiological and neurological outcomes}

These data are summarized in Table 2. No statistical difference was found in the radiological measurements of $\mathrm{ADI}, \mathrm{CCA}, \mathrm{CL}$, and CMA between the two groups before operation. These parameters in both groups had significant improvements after operation. The ADI and CL in the TARP group were significantly less than those in the OF group at the discharge and at the 3-month follow-up $(p<.01)$. The CCA and CMA in the TARP group were significantly greater than those in the OF group at the discharge and at the 3-month follow-up $(p<.01)$. There was no difference in the JOA score between two groups before operation $(p=.34)$. Significant improvement of JOA score was reflected in both groups postoperatively, but the JOA score in two groups had no statistical difference at discharge. However, when analyzing the data at 3-, 6- and 12-month follow-ups, the JOA scores in the TARP group were significantly higher than those in the OF group $(p<.01 ; p<.01)$. 
Table 1 The clinical and surgical data of 56 patients

\begin{tabular}{|c|c|c|c|}
\hline Characteristic & TARP group & OF group & $P$ \\
\hline Number of patients/n & 35 & 21 & \\
\hline Sex/n(\%) & & & .18 \\
\hline Male & $14(40.0 \%)$ & $9(42.9 \%)$ & \\
\hline Female & $21(60.0 \%)$ & $12(57.1 \%)$ & \\
\hline Age/y (range) & $42.5 \pm 15.6(12-70)$ & $38.6 \pm 14.2(14-71)$ & .35 \\
\hline \multicolumn{4}{|l|}{ Symptom presentation/n (\%) } \\
\hline Extremities weakness & $34(97.1 \%)$ & 19 (90.5\%) & .54 \\
\hline Numbness & $27(77.1 \%)$ & $13(61.9 \%)$ & .33 \\
\hline Occipital and neck pain & $22(62.9 \%)$ & $12(57.1 \%)$ & .67 \\
\hline Dystaxia & $13(37.1 \%)$ & $5(23.8 \%)$ & .30 \\
\hline Dyspnea & $5(14.3 \%)$ & $2(9.5 \%)$ & .70 \\
\hline Others & $11(31.4 \%)$ & $6(28.6 \%)$ & .82 \\
\hline \multicolumn{4}{|l|}{ Concomitant malformation/n (\%) } \\
\hline Atlas assimilation & $29(82.9 \%)$ & 18 (85.7\%) & .78 \\
\hline Klippel-Feil syndrome & $10(28.5 \%)$ & $4(19.0 \%)$ & .12 \\
\hline Chiari malformation & $5(14.3 \%)$ & $2(9.5 \%)$ & .70 \\
\hline Syringomyelia & $13(37.1 \%)$ & $6(28.5 \%)$ & .51 \\
\hline Symptom treatment interval/months (range) & $63.2 \pm 50.4(12-240)$ & $49.9 \pm 55.8(6-240)$ & .36 \\
\hline Operative time/min (range) & $227.6 \pm 61.5(90-420)$ & $325.2 \pm 123.4(150-600)$ & $<.01$ \\
\hline Blood loss/ml (range) & $123.1 \pm 54.9(50-250)$ & $271.4 \pm 142.8(50-500)$ & $<.01$ \\
\hline Postoperative complications/n (\%) & $3(8.5 \%)$ & $1(4.7 \%)$ & .59 \\
\hline Pulmonary infections & $1(2.9 \%)$ & 0 & \\
\hline Deep vein thromboses & $1(2.9 \%)$ & 0 & \\
\hline Urinary tract infections & $1(2.9 \%)$ & $1(4.7 \%)$ & \\
\hline Follow-up/months & $36.6 \pm 16.0(12-72)$ & $41.6 \pm 18.1(12-84)$ & .29 \\
\hline
\end{tabular}

TARP Transoral atlantoaxial reduction plate, OF Occipitocervical fixation, Others Including dizziness, sleep apnea, tinnitus, hoarseness, dysfunction of excretion

The bone fusion rates were higher in the TARP group than those in the OF group at 3- and 6-month followups $(p<.05 ; p<.05)$. There was no significant difference in the bone fusion rates between groups at the 12month follow-up, with $100 \%$ of fusion was achieved in the TARP group and $95.2 \%$ in the OF group. Finally, one patients (4.7\%) in the OF group did not obtain bone fusion at the subsequent follow-up and the final fusions were achieved after a revision surgery with cancellous bone grafting. During the full follow-up period, no signs of re-dislocation or instrument failure and other late complications were documented in both groups.

\section{Discussion}

$\mathrm{BI}$, accompanied by IAAD, invariably results in evolutionary compression of the medulla, leading to severe neurological damage and even death. Surgical treatment is often required for most patients to restore the dislocation, reconstruct stability, relieve clinical symptoms [14]. At present, OF operation is the most popular posterior surgical procedure for treating BI with IAAD using plate-screw-rod instruments [9-13]. The TARP system was designed by Yin et al. in 2004, and it is an effective surgical approach for treating irreducible atlantoaxial dislocation caused by congenital developmental anomaly, tumour, trauma, and so on, completing release, reduction, decompression, fixation, and fusion in one step with an anterior-only approach [15-17]. For treatment of BI with IAAD, the TARP system possesses distinctive advantages, because it can move down the odontoid process from the foramen magnum and achieve reduction to directly relieve the compression anterior to the spinal cord $[5,6]$.

Several clinical studies have confirmed the effectiveness of TARP and OF operation for the treatment of BI with IAAD, but all involved a single surgical procedure [5-13]. We retrospectively analyzed the clinical profiles of 56 patients diagnosed with BI with IAAD who underwent a TARP or OF operation, with the aim of comparing the two treatments for BI with IAAD.

In this study, patients undergoing TARP or OF operation obtained significant radiological improvement in 


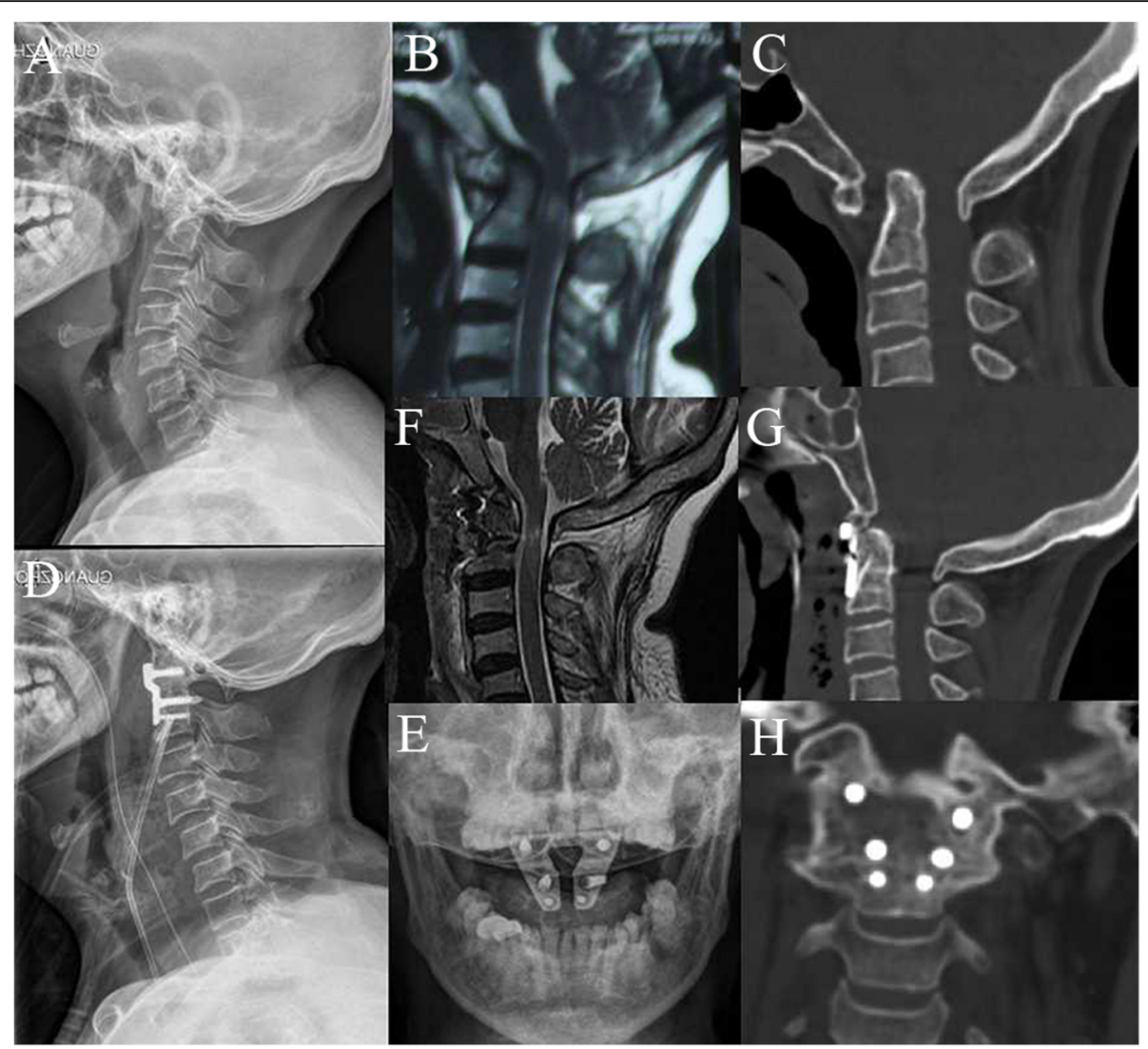

Fig. 1 A 64-year-old woman, diagnosed with basilar invagination with atlantoaxial dislocation, underwent a TARP procedure. Images of cervical lateral radiographs (a), sagittal MRI (b), and sagittal CT scan (c) before surgery showed evidence of basilar invagination with atlantoaxial dislocation and compression on the ventral medulla. Cervical radiographs (d, e) after a TARP operation showed well placement of device. Postoperative sagittal MRI (f) and sagittal CT scan $(\mathbf{g})$ showed reduction of atlantoaxial dislocation with descent of the odontoid process and decompression on the ventral medulla. CT image (h) at 3 months after surgery revealed solid bone fusion

postoperative $\mathrm{ADI}, \mathrm{CCA}, \mathrm{CL}$ and CMA demonstrating the effect of two surgical approaches for reduction and decompression. Moreover, postoperative JOA scores in all patients obviously improved. The aforementioned result explains that the use of a TARP or OF operation is an effective surgical approach for the treatment of BI with IAAD, consistent with previous studies.

Found in comparative analysis of surgical characteristics, the operative time and blood loss in the TARP group were less than those in the OF group, which might because the TARP operation can be performed with an transoral anterior-only approach [5-8, 15-17], while OF operation often requires concomitant transoral anterior release before the posterior approach is made in order to achieve satisfactory reduction and decompression [9-13]. Otherwise, operative time and blood loss would be increased, leading to a wider range of surgical trauma and a higher risk of infection. Furthermore, the spinal cord might have been injured while in the transforming operative position after transoral anterior release when the atlantoaxial joint was extremely unstable [14].
Although no significant differences were found in the preoperative radiographic measurements of $\mathrm{ADI}, \mathrm{CCA}$ $\mathrm{CL}$, and CMA between the TARP and OF groups, compared with OF, the improvements of postoperative ADI, CMA, CCA, and CL in the TARP group were superior. This indicates that TARP operation was more effective than OF operation in reducing BI with IAAD, bound up with a more direct method of reduction by TARP than by OF. By using reduction instruments directly in TARP procedures, we were able to separate the atlantoaxial junction and pull the axis with the odontoid process inferiorly and subsequently push $\mathrm{C} 1$ backward relative to $\mathrm{C} 2$. We thus achieved atlantoaxial reduction, while OF procedures reduced the atlantoaxial junction to allow the axis, with the odontoid process, to descend indirectly via the strength generated by the posterior plate-screwrod instruments.

Satisfactory neurological improvements were achieved in both the TARP and OF groups after operations. Despite no difference in preoperative JOA scores between two groups at discharge, the JOA score of the TARP 


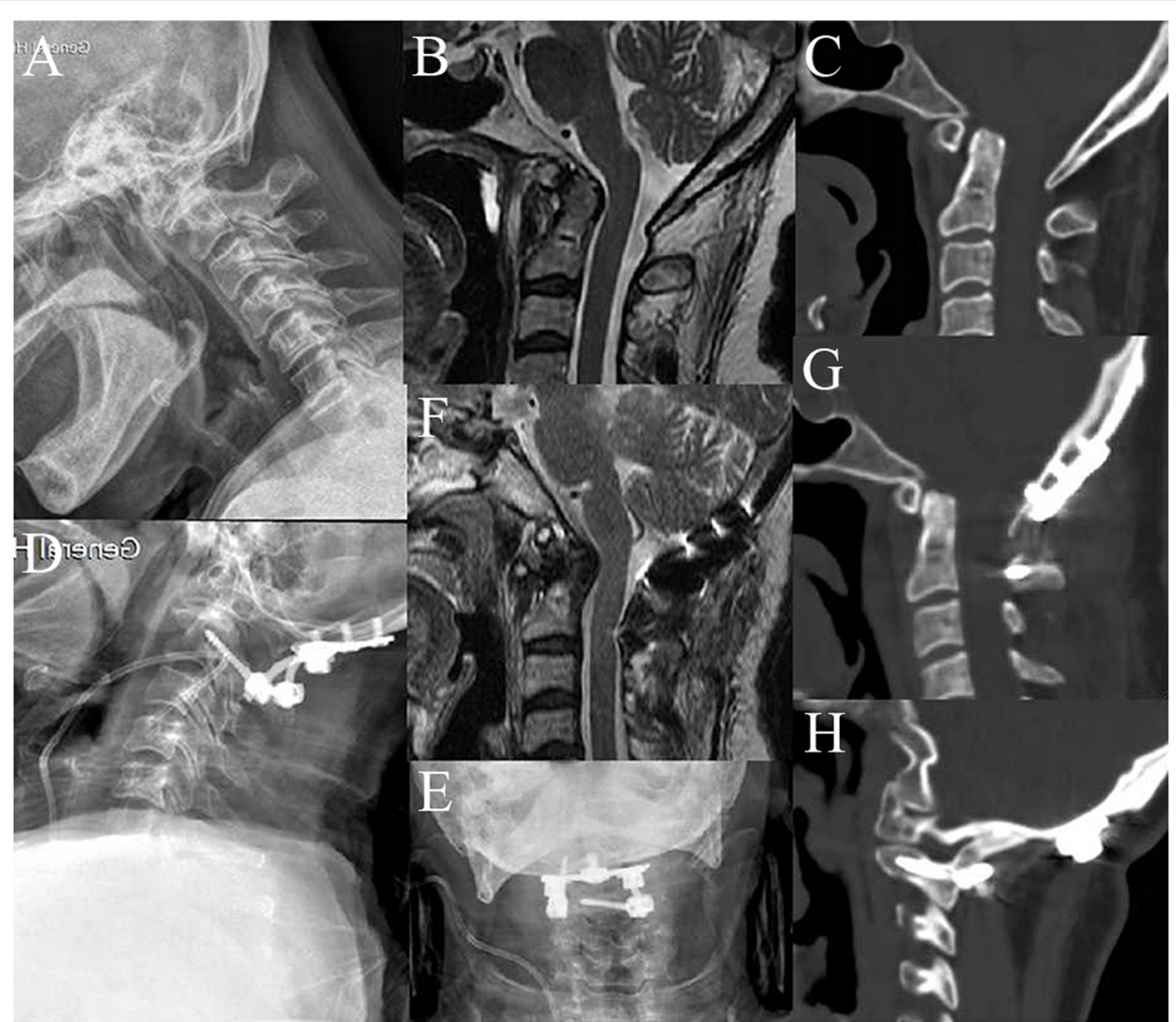

Fig. 2 A 62-year-old man, diagnosed with basilar invagination with atlantoaxial dislocation, underwent an OF surgery. Preoperative images of cervical lateral radiographs (a), sagittal CT scan (b), and sagittal MRI (c) showed evidence of basilar invagination with atlantoaxial dislocation and compression on the ventral. Cervical lateral radiographs (d, e) after an OF operation showed satisfactory location of internal fixation. Postoperative sagittal MRI (f) and sagittal CT scan (g) showed repositioning of atlantoaxial dislocation and alleviation of compression on the medulla. CT image (h) from the 6-month follow-up showed solid bone fusion

group was significantly higher than that in the OF group at the 3-, 6- and 12-month follow-ups. Patients with BI and IAAD suffered from ventral spinal cord compression induced by ascent of the odontoid process. Jiang et al. [18] reported that the craniocervical volume change rate is a positive predictor for evaluating the improvement of postoperative neurological function in patients with BI. The study by Wei et al. [16] confirmed the negative correlation between the CL and the craniocervical volume improvement rate. The postoperative CL in TARP group was significantly less than that in OF group, so that, the function of TARP operation for improving craniocervical volume could be more obvious than that of OF, which could be more beneficial for recovering of impaired spinal nerves.

We also found that the bone fusion rate was much higher at the early stage postoperatively in the TARP group than that in the OF group. It might be related to methods of bone grafting in two procedures. Although, both TARP and OF fixation had a excellent biomechanical stability proved by previous researches [19-21], more pressure was put on bone grafts in TARP procedure than in OF operation, because most bone was grafted into the lateral mass joint space in TARP operation [22], while all bone was grafted on the surfaces of $\mathrm{C} 1$ posterior arch, $\mathrm{C} 2$ lamina, and lower part of the occipital in OF operation [23].

Wound infection is another concern. Most surgeons select OF fixation mainly because of this complication. TARP fixation might be more possible to cause the occurrence and spread of infection [24-26]. But, with proper preoperative preparation and postoperative care, the complication rate can be reduced. In this study, no patient had wound infection in TARP group.

There are several limitations in this study. Selection bias exists in this study due to the single-center analysis, that hints the requirement of a multicenter, large sample study in the future. Additionally, the present study is retrospective in nature; future prospective studies may better control for follow-up timing intervals and may have the potential to include more standardized outcome measures.

\section{Conclusions}

The TARP and OF operations are effective surgical approaches for treating BI with IAAD. However, the 
Table 2 Comparisons of pre- and postoperative radiological and neurological evaluation between the two groups

\begin{tabular}{|c|c|c|c|}
\hline Items & TARP group & OF group & $P$ \\
\hline \multicolumn{4}{|l|}{$\mathrm{ADI} / \mathrm{mm}$} \\
\hline Before operation & $6.3 \pm 2.3$ & $5.7 \pm 1.9$ & .31 \\
\hline At discharge & $1.9 \pm 1.1$ & $2.9 \pm 1.2$ & $<.01$ \\
\hline 3-month follow-up & $1.9 \pm 1.1$ & $2.9 \pm 1.2$ & $<.01$ \\
\hline \multicolumn{4}{|l|}{$\mathrm{CL} / \mathrm{mm}$} \\
\hline Before operation & $11.1 \pm 3.5$ & $10.2 \pm 4.8$ & .43 \\
\hline At discharge & $1.0 \pm 1.8$ & $3.0 \pm 3.1$ & $<.01$ \\
\hline 3-month follow-up & $1.0 \pm 1.8$ & $3.0 \pm 3.1$ & $<.01$ \\
\hline \multicolumn{4}{|l|}{$\mathrm{CCA} /^{\circ}$} \\
\hline Before operation & $122.1 \pm 14.7$ & $123.1 \pm 18.0$ & .82 \\
\hline At discharge & $151.5 \pm 10.2$ & $139.5 \pm 17.2$ & $<.01$ \\
\hline 3-month follow-up & $151.8 \pm 10.1$ & $139.6 \pm 17.2$ & $<.01$ \\
\hline \multicolumn{4}{|l|}{$\mathrm{CMA}^{\circ}$} \\
\hline Before operation & $125.4 \pm 10.9$ & $130.1 \pm 16.4$ & .20 \\
\hline At discharge & $156.4 \pm 7.1$ & $145.0 \pm 14.2$ & $<.01$ \\
\hline 3-month follow-up & $157.0 \pm 6.9$ & $145.3 \pm 14.3$ & $<.01$ \\
\hline \multicolumn{4}{|l|}{ JOA score } \\
\hline Before operation & $10.7 \pm 1.5$ & $11.1 \pm 1.3$ & .34 \\
\hline At discharge & $12.6 \pm 1.3$ & $12.0 \pm 1.0$ & .06 \\
\hline 3-month follow-up & $13.8 \pm 1.0$ & $13.0 \pm 0.9$ & $<.01$ \\
\hline 6-month follow-up & $14.3 \pm 0.8$ & $13.7 \pm 0.6$ & $<.01$ \\
\hline 12-month follow-up & $15.4 \pm 1.00$ & $14.5 \pm 0.9$ & $<.01$ \\
\hline \multicolumn{4}{|l|}{ Bone fusion/n (\%) } \\
\hline 3-month follow-up & $22(62.9 \%)$ & 7 (33.3\%) & .03 \\
\hline 6-month follow-up & $30(85.7 \%)$ & $13(61.9 \%)$ & .04 \\
\hline 12-month follow-up & $35(100 \%)$ & $20(95.2 \%)$ & .36 \\
\hline Final follow-up & 35 (100\%) & $21(100 \%)$ & NS \\
\hline
\end{tabular}

$A D I$ Atlantodental interval, CCA Clivus canal angle, CL Distance between the top of the odontoid process and the Chamberlain line, CMA Cervicomedullary angle, JOA Japanese Orthopaedic Association, NS Not significant

TARP procedure offers a more direct and ideal performance than does OF in reduction and decompression. Moreover, TARP operation could obtain earlier solid bone fusion. The TARP technique may be a superior choice for treatment of BI with IAAD.

\section{Abbreviations}

TARP: Transoral atlantoaxial reduction plate; OF: Occipitocervical fixation; BI: Basilar invagination; IAAD: Irreducible atlantoaxial dislocation: ADI: Atlantodental interval; CCA: Clivus canal angle; CL: Distance between the top of the odontoid process and the Chamberlain line; CMA: Cervicomedullary angle; JOA: Japanese Orthopaedic Association; CT: Computed tomography; MRI: Magnetic resonance imaging; NS: Not significant

\section{Acknowledgements}

We would like to thank Zenghui Wu, Jianhua Wang, Kai Zhang, Fuzhi Ai for guidance of measurement of radiographic data.

\section{Authors' contributions}

MX designed the study and critically revised the manuscript. ZX, OB, YH carried out the statistical analyses, and drafted the manuscript. WB, GS, CY, $\mathrm{NL}$, ZS were responsible for the data collection and measurement of radiographic data. YJ, XH checked the manuscript. All authors read and approved the final manuscript.

\section{Funding}

This work was supported by the Guangzhou Municipal Science and Technology Project (No. 201803010046); the National Natural Science Foundation of China (No. 81672232); and the Science and Technology Planning Project of Guangdong Province (No. 2015B020233013).

\section{Availability of data and materials}

The data used and analyzed during the current study are available in anonymized form from the corresponding author on reasonable request.

\section{Ethics approval and consent to participate}

This stud y was approved by the ethics committee of General Hospital of Southern Theatre Command of PLA and the written informed consent for participation in the study was obtained.

\section{Consent for publication}

Written informed consent was obtained from all individual participants included in the study.

\section{Competing interests}

The authors declare that they have no competing interests.

\section{Author details}

'The First School of Clinical Medicine, Southern Medical University, No.1838 North of Guangzhou Road, Guangzhou 510515, People's Republic of China. ${ }^{2}$ Department of Orthopedics, General Hospital of Southern Theatre Command of PLA, No.111 Liuhua Road, Guangzhou 510010, People's Republic of China. ${ }^{3}$ Department of Spinal Surgery, Nanfang Hospital,

Southern Medical University, No.1838 North of Guangzhou Road, Guangzhou 510515, People's Republic of China.

Received: 1 September 2020 Accepted: 25 November 2020

\section{Published online: 08 December 2020}

\section{References}

1. Smith JS, Shaffrey $\mathrm{Cl}$, Abe MF, Menezes AH. Basilar invagination. Neurosurgery. 2010;66:A39-46.

2. Goel A, Jain S, Shah A. Radiological evaluation of 510 cases of basilar invagination with evidence of atlantoaxial instability (group a basilar invagination). World Neurosurg. 2018;1 10:533-43.

3. Klekamp J. Treatment of basilar invagination. Eur Spine J. 2014;23:1656-65.

4. Liao Y, Pu L, Guo H, Mai E, Liang W, Deng Q, Xu T, Sheng J, Sheng W. Selection of surgical procedures for basilar invagination with atlantoaxial dislocation. Spine J. 2016;16:1184-93.

5. Yin QS, Li XS, Bai ZH, Mai XH, Xia H, Wu ZH, Ma XY, Ai FZ, Wang JH, Zhang K. An 11-year review of the TARP procedure in the treatment of atlantoaxial dislocation. Spine (Phila Pa 1976). 2016;41:E1151-8.

6. Yin QS, Ai FZ, Zhang K, Mai XH, Xia H, Wu ZH. Transoral atlantoaxial reduction plate internal fixation for the treatment of irreducible atlantoaxial dislocation: a 2- to 4-year follow-up. Ortho Surg. 2010;2:149-55.

7. Wei G, Wang Z, Ai F, Yin Q, Wu Z, Ma XY, Xu J, Shi C, Xia H. Treatment of basilar invagination with Klippel-Feil syndrome: atlantoaxial joint distraction and fixation with Transoral Atlantoaxial reduction plate. Neurosurgery. 2016; 78:492-8.

8. Lan S, Xu J, Wu Z, Xia H, Ma X, Zhang K, Ai F, Wang J, Yin Q, Yi H, Duan M. Atlantoaxial joint distraction for the treatment of basilar invagination: clinical outcomes and radiographic evaluation. World Neurosurg. 2018;111: e135-41.

9. Peng $X$, Chen $L$, Wan $Y$, Zou X. Treatment of primary basilar invagination by cervical traction and posterior instrumented reduction together with occipitocervical fusion. Spine (Phila Pa 1976). 2011;36:1528-31.

10. Jian FZ, Chen Z, Wrede KH, Samli M, Ling F. Direct posterior reduction and fixation for the treatment of basilar invagination with atlantoaxial dislocation. Neurosurgery. 2010;66:678-87. 
11. Srivastava SK, Aggarwal RA, Nemade PS, Bhosale SK. Single-stage anterior release and posterior instrumented fusion for irreducible atlantoaxial dislocation with basilar invagination. Spine J. 2016;16:1-9.

12. Wang C, Yan M, Zhou HT, Wang SL, Dang GT. Open reduction of irreducible atlantoaxial dislocation by transoral anterior atlantoaxial release and posterior internal fixation. Spine (Phila Pa 1976). 2006;31:E306-13.

13. Wang Q, Mao K, Wang C, Mei W. Transoral Atlantoaxial release and posterior reduction by occipitocervical plate fixation for the treatment of basilar invagination with irreducible atlantoaxial dislocation. J Neurol Surg A Cent Eur Neurosurg. 2017;78:313-20.

14. Yang J, Ma X, Xia H, Wu Z, Ai F, Yin Q. Transoral anterior revision surgeries for basilar invagination with irreducible atlantoaxial dislocation after posterior decompression: a retrospective study of 30 cases. Eur Spine J. 2014;23:1099-108.

15. Yin Q, Ai F, Zhang K, Chang Y, Xia H, Wu Z, Quan R, Mai X, Liu J. Irreducible anterior atlantoaxial dislocation: one-stage treatment with a transoral atlantoaxial reduction plate fixation and fusion. Report of 5 cases and review of the literature. Spine (Phila Pa 1976). 2005;30:E375-81.

16. Wei G, Shi C, Wang Z, Xia H, Yin Q, Wu Z. Surgical outcome and prognostic analysis of transoral atlantoaxial reduction plate system for basilar invagination: a voxel-based Morphometry study. J Bone Joint Surg Am. 2016:98:1729-34.

17. Xia H, Yin Q, Ai F, Ma X, Wang J, Wu Z, Zhang K, Liu J, Xu J. Treatment of basilar invagination with atlantoaxial dislocation: atlantoaxial joint distraction and fixation with transoral atlantoaxial reduction plate (TARP) without odontoidectomy. Eur Spine J. 2014:23:1648-55.

18. Jiang YW, Xia H, Wang ZY, Wu ZH, Ma XY, Wei GJ, Ma LM, Huang JL, Zheng $G$, Feng XL. Variation of craniocervical junction volume as an effective parameter for basilar invagination treatment. Eur Rev Med Pharmacol Sci. 2015;19:1754-60

19. Zhang B, Liu H, Cai X, Wang Z, Xu F, Liu X, Wang H, Kang H, Ding R. Biomechanical comparison of modified TARP technique versus modified Goel technique for the treatment of basilar invagination: a finite element analysis. Spine (Phila Pa 1976). 2016;41:E459-66.

20. Anderson PA, Oza AL, Puschak TJ, Sasso R. Biomechanics of occipitocervical fixation. Spine (Phila Pa 1976). 2006;31:755-61.

21. Gabriel JP, Muzumdar AM, Khalil S, Ingalhalikar A. A novel crossed rod configuration incorporating translaminar screws for occipitocervical internal fixation: an in vitro biomechanical study. Spine J. 2011;11:30-5.

22. Huang X, Yin Q, Wang Z, Xia H. Implantation of the anterior atlantoaxial lateral mass intervertebral cage using the transoral approach. J Orthop Sci. 2017;22:630-4

23. Winegar CD, Lawrence JP, Friel BC, Fernandez C, Hong J, Maltenfort M Anderson PA, Vaccaro AR. A systematic review of occipital cervical fusion: techniques and outcomes. J Neurosurg Spine. 2010;13:5-16.

24. Landeiro JA, Boechat S, Christoph DH, Gonçalves MB, Castro ID, Lapenta MA, Ribeiro CH. Transoral approach to the craniovertebral junction. Arq Neuropsiquiatr. 2007:65:1166-71.

25. Tubbs RS, Demerdash A, Rizk E, Chapman JR, Oskouian RJ. Complications of transoral and transnasal odontoidectomy: a comprehensive review. Childs Nerv Syst. 2016;32:55-9.

26. Wu Z, Xu J, Wang Z, Xia H, Zhang Q, Ma X, Zhang K. Transoral approach for revision surgery of os odontoideum with atlantoaxial dislocation. Orthopedics. 2014;37(9):e851-5.

\section{Publisher's Note}

Springer Nature remains neutral with regard to jurisdictional claims in published maps and institutional affiliations.

Ready to submit your research? Choose BMC and benefit from:
- fast, convenient online submission
- thorough peer review by experienced researchers in your field
- rapid publication on acceptance
- support for research data, including large and complex data types
- gold Open Access which fosters wider collaboration and increased citations
- maximum visibility for your research: over 100M website views per year
At BMC, research is always in progress.
Learn more biomedcentral.com/submissions

